\title{
LA ACCIÓN DE AMPARO EN HONDURAS VISIÓN HACÍA UNA PROTECCIÓN JUDICIAL EFECTIVA
}

\section{Mauricio José Cantor Rosales ${ }^{1}$}

\section{RESUMEN:}

El presente artículo principia realizando un análisis, descripción y explicación de la evolución normativa de uno de nuestros mecanismos de protección judicial, a saber, la acción de amparo, ello con el objetivo de identificar los obstáculos jurídicos que se han presentado a lo largo del desarrollo histórico de nuestro mecanismo de protección constitucional, para así precisar los motivos por los cuales la justicia constitucional se ha visto limitada en la transición de las diversas leyes que han regulado el juicio de Amparo.

Asimismo, se describen los estándares internacionales fijados por la Corte Interamericana de Derechos Humanos en materia de protección judicial, ello con el propósito de individualizar problemas jurídico normativos presentes en la legislación vigente de amparo que condicionan la dignidad humana a la luz del principio pro homine de protección a los derechos humanos, todo lo anterior para brindar una perspectiva real de la necesidad de modernizar nuestra normativa reguladora de esta garantía constitucional y ofrecer una tutela judicial efectiva para la defensa de los derechos humanos y derechos fundamentales de los ciudadanos.

PALABRAS CLAVE: Acción de Amparo, Derechos humanos, Derechos Fundamentales, Ley sobre Justicia Constitucional, Protección Judicial, Control de Convencionalidad, Control de Constitucionalidad. 


\section{THE ACTION OF PROTECTION IN HONDURAS VISION TOWARDS AN EFFECTIVE JUDICIAL PROTECTION}

\section{Mauricio José Cantor Rosales*}

\section{ABSTRACT:}

The following article begins by making an analysis, description, and explanation of the evolution of the normative of one of our judicial protection's mechanisms, and to know the action of protection. This has the objective of identifying judicial obstacles that have presented throughout the long historical development of our constitutional protection's mechanisms, and to name the reasons why constitutional justice has become limited in its transition towards various laws that have regulated the judgement of protection.

Furthermore, the international standards set by the Inter - American Court of the Human Rights in matter of judicial protection are described, with the purpose of individualizing the normative - judicial problems that are present in the current legislation of protection that determine human dignity in the light of the pro homine and maximizing integrity of the Inter - American system of protection of the human rights. All the things mentioned above is to bring upon a real perspective of the need of upgrading our regulatory normative of this constitutional guarantee and offer an effective judicial guardianship for the defense of human rights and fundamental rights of the citizens.

KEYWORDS: Action of Protection, Human Rights, Fundamental Rights, Law on Constitutional Justice, Judicial Protection, Conventionality Control, Constitutional Control.

Received: July 3, 2018

Approved: September 18, 2018

${ }^{\star}$ Lawyer graduated from the National Autonomous University of Honduras. Legal Advisor of the Decanatura of the Faculty of Legal Sciences, National Autonomous University of Honduras. Email: mauri.rosales92@gmail.com 


\section{INTRODUCCIÓN}

La acción de amparo es una institución del derecho procesal constitucional, y, a su vez, concebida como un mecanismo de control constitucional, cuyo objetivo primordial es tutelar los derechos humanos o fundamentales de las personas sujetas a la jurisdicción hondureña contra las arbitrariedades del poder público, aportando, para tales motivos, un instrumento rápido, sencillo y eficaz para reparar el daño ocasionado al bien jurídico vulnerado.

La historia constitucional hondureña ha estado marcada por una serie de infortunios producto de los problemas políticos, económicos y sociales. En consecuencia, Honduras tendría un total de trece constituciones, dentro de las cuales y, debido a la influencia del derecho mexicano en los demás países latinoamericanos en materia de protección de garantías individuales (Poisot, 2010), la constitución emitida el 14 de octubre de 1894 reconocería por primera vez la garantía constitucional de Amparo. Esta disposición dotaría al Poder Judicial de facultades suficientes para proteger a los ciudadanos oprimidos por los empleados del poder político que abusaban de su fuerza.

Así, los procesos constituyentes y reformistas dieron lugar a que existieran múltiples cuerpos normativos adjetivos de amparo, llegando a tener hasta la fecha un total de seis leyes en la historia sobre justicia constitucional hondureña, partiendo con la Ley Reglamentaria del Juicio de Amparo de 1893, la ley de amparo emitida el 8 de febrero de 1906, seguida por la del 11 de marzo de 1908; la del 30 de septiembre de 1924 y, la emitida el 14 de abril de 1936, la cual tendría una vigencia de 68 años hasta ser derogada por la actual y vigente Ley sobre Justicia Constitucional en el año 2004.

Posteriormente a los sucesos acontecidos en la segunda guerra mundial, la historia del derecho constitucional e internacional cambiaria significativamente con el surgimiento de la Declaración Universal de los Derechos Humanos el 10 de diciembre de 1948, pues se reconocería un conjunto de preceptos jurídicos esenciales, inherentes y universales a toda persona humana, indistintamente de su nacionalidad, raza, sexo, religión o cualquier denominación análoga.

Lo anterior, ocasionaría que desde esa fecha comenzara a plantearse y desarrollarse las implicaciones jurídicas del término "dignidad humana", entendiéndose como un principio rector de la hermenéutica legal que proyecta su luz sobre los derechos individuales de las personas, enriqueciéndolos con nuevos significados, y que orienta la actividad normativa y jurisprudencial, encaminando a la autoridad competente a tomar decisiones que aseguren un mayor grado de efectividad en el respeto y garantía de los derechos humanos o fundamentales. (Fernández, 1995).

En ese sentido, el presente articulo comienza realizando un análisis, descripción y explicación de la evolución normativa de nuestra acción de amparo, la cual permitirá apreciar el tratamiento que se le otorgaba a esta garantía constitucional en los cuerpos normativos que lo regularon desde 1894 hasta la actualidad, esto con el objetivo de identificar los obstáculos jurídicos que se han presentado a lo largo del desarrollo histórico de nuestro mecanismo de protección constitucional, para así precisar los motivos por los cuales la justicia constitucional se ha visto limitada en la transición de las diversas leyes que regularon el juicio de amparo.

Asimismo, se describen los estándares internacionales fijados por la Corte Interamericana de Derechos Humanos en materia de protección judicial, mismos que permitirán ahondar en la naturaleza protectora del Amparo, ello con el propósito de individualizar problemas jurídico normativos presentes en la legislación vigente de amparo que condicionan la dignidad humana a la luz del principio pro homine de protección a los derechos humanos. 
Todo lo anterior servirá para ilustrar una perspectiva real de la necesidad de modernizar nuestra normativa reguladora de la garantía constitucional de amparo y; así, ofrecer una tutela judicial efectiva para la defensa de los derechos humanos y derechos fundamentales de los ciudadanos.

\section{METODOLOGÍA:}

La investigación es de tipo formal desarrollada a través de metodología descriptiva, analítica y explicativa, en virtud fue más allá de una escueta lectura normativa y doctrinaria. Del orden formal por cuanto se hace meramente teórico, obviando cualquier observación del orden experimental; descriptiva, por cuanto se especifican y detallan diversos aspectos jurídicos sobre el funcionamiento de la norma e institución jurídica del amparo y; analítica y explicativa, en virtud que se realiza un examen detallado del amparo, sus características, estándares, evolución jurídica y jurisprudencia relacionada, todo ello dirigido a exponer problemáticas, causas y fenómenos presentes en el cuerpo normativo regulador de esta garantía constitucional.

\section{EVOLUCIÓN NORMATIVA DE LA ACCIÓN DE AMPARO}

En relación con las leyes procesales constitucionales comprendidas entre los años 1893 a 1936, la justicia constitucional en materia de garantías individuales permanecería uniforme e inalterable por más de cuatro décadas, pues todas estas leyes establecerían una serie de elementos repetitivos que serían el resultado de una copia constante de las disposiciones de sus predecesoras. Así pues, como primer elemento, puede destacarse la legitimación pasiva, la cual determinaba que la acción de amparo procedía contra las resoluciones, actos y hechos realizados por cualquier autoridad o funcionario que obrara por sí o en cumplimiento de una ley. Es importante destacar que este elemento recoge el axioma jurídico en donde los funcionarios públicos eran considerados los únicos trasgresores de los derechos humanos o fundamentales, en virtud que sus actos eran exclusivos de ser reclamados por la vía judicial constitucional.

Como segundo punto, el derecho a solicitar el amparo y la legitimación activa con que obrara la parte recaía en todo momento sobre el agraviado o cualquier persona que actuara en nombre de ésta, debiendo hacerlo por escrito y dentro del plazo de sesenta días. Asimismo, la competencia estaría a cargo de la Corte Suprema de Justicia, Cortes de Apelaciones y Juzgados de Letras, quienes conocerían sobre la acción de garantía dentro del marco de sus respectivas competencias y potestades jurisdiccionales previamente definidas y delimitadas por la ley.

En relación con la sustanciación de la acción se consagraba un proceso sumamente engorroso, ya que una vez presentado el escrito, el Juzgador debía analizar si se cumplía con los requisitos de admisibilidad (aspectos de forma) y, en caso de adolecer de algún defecto procesal, la acción era sobreseída in limine litis; si, por el contrario, se cumplían con todos los presupuestos procesales, se emitía auto de admisión, en donde el órgano jurisdiccional que conocía la causa ordenaba la remisión de antecedentes o informe a la autoridad o empleado público contra quien se interpone el amparo, quienes debían cumplir con esa obligación en un término de veinticuatro horas más un día extra por cada veinte kilómetros de distancia en donde se encontrara el agente estatal. En esta etapa de admisibilidad, la acción de amparo no contaba con una tramitación de carácter preferente; por consiguiente, el impulso procesal que daba el juzgador dependía en todo momento de la carga judicial del tribunal, supeditando a que otros actos procesales que no guardaran relación con la tutela constitucional tuvieran preeminencia sobre este mecanismo de protección judicial.

Recibidos los antecedentes o, en su caso, el informe de la autoridad, se otorgaba un plazo de cuarenta y ocho horas al recurrente para que 
formalizara la petición por escrito, este mismo término era otorgado al Fiscal del Ministerio Público, quien, a la vista de los antecedentes y la petición del quejoso, debía presentar el dictamen en donde se pronunciaría sobre el otorgamiento de la garantía constitucional. Habiendo realizado estas acciones judiciales, el juzgador valoraba si la acción incoada contaba con características de ser un asunto de mero derecho, si este era el caso, emitía sentencia dentro del plazo de tres días.

Sin embargo, si existían hechos que debían ser probados, se daba un plazo de ocho días para apertura y evacuación de medios de prueba $\mathrm{y}$, en caso de existir circunstancias que debían ser acreditadas fuera de sede judicial, este plazo podía ser extendido en un día por cada veinte kilómetros de distancia. Concluido el plazo a prueba, las partes debían formular sus alegatos finales ante el órgano jurisdiccional en las siguientes veinticuatro horas. Finalizada esta etapa procesal, el tribunal debía emitir sentencia otorgando o sobreseyendo la acción.

Finalmente, los efectos de la sentencia en los juicios de amparo seguiría los lineamientos de la doctrina jurídico - constitucional, a través de la cual el acto reclamado en vía de amparo debía atender a un agravio personal y enmarcarse dentro de los límites del restablecimiento al estado anterior a la lesión o amenaza de lesión del derecho fundamental, pues, solo sería viable acudir ante la justicia constitucional si el acto reclamado cumple tal presupuesto; contrario sensu, se estaría frente a una circunstancia que, por la naturaleza del hecho y despliegue de los efectos jurídicos y materiales del acto lesivo, resultaría imposible obtener el efecto restitutorio que brinda el amparo (Yupanqui, 2004).

Con el inicio del siglo XXI, Honduras experimentaría una evolución en su derecho sobre justicia constitucional, y, sobre todo, en la tramitación de la acción de amparo, pues su predecesora del año 1936 resultaba insuficiente para adaptarse a las necesidades normativas imperantes durante esta nueva era, ya que en su regulación no se contemplaba con un mecanismo sencillo, eficaz y sin formalidades engorrosas en la tramitación de las acciones constitucionales. De esta manera, se aprobaría la Ley sobre Justicia Constitucional mediante Decreto Legislativo Nro. 244 - 2003, cuya finalidad estaría orientada a brindar una correcta correspondencia de las garantías constitucionales a la luz de la normativa emanada de la Carta Magna, tratados y convenciones ratificados por el Estado de Honduras.

La Ley sobre Justicia Constitucional permanecería fiel a seguir determinados lineamientos procesales de las leyes anteriores, como, por ejemplo, el derecho a interponer el amparo recaería nuevamente sobre el agraviado o cualquier persona interesada, se mantendría el mismo plazo de interposición, así como también los términos legales de formalización de la petición, vista al Fiscal del Ministerio Público, período general probatorio, emisión y efectos jurídicos de la sentencia.

No obstante, pese a mantener estos aspectos en común, se logró derrumbar algunos obstáculos jurídicos que se presentaban en el pasado mediante la introducción de una serie de elementos procesales que permitirían efectivizar el juicio constitucional, tales como la posibilidad de subsanar si existían falta de requisitos legales; se reconocería el principio de prelación del amparo, mediante el cual se obliga al órgano jurisdiccional a dar impulso procesal el mismo día de su presentación o al día hábil siguiente; asimismo, se establecería un mecanismo de vía de apremio para obligar a la autoridad o funcionario público que se negara acatar el mandato judicial recaído en la sentencia de amparo. Finalmente, los plazos serían de carácter más riguroso y se derogaría la disposición con la cual se otorgaba una extensión del plazo por distancia territorial, esto contribuiría al cumplimiento del principio de perentoriedad de los plazos y se acoplaría a la realidad social del siglo XXI. 
En relación con los elementos innovadores que esta ley traería para dinamizar la protección judicial de los derechos humanos y fundamentales, puede destacar como primer elemento, la introducción de las normas y reglas de interpretación, ya que a través de este precepto la Corte Suprema de Justicia emprendería un proceso de acoplamiento paulatino de la normativa internacional al ordenamiento jurídico hondureño, en virtud que en los casos AA406-2013, RI-1343-2014, este último acumulado con el RI-243-2015, al alto Tribunal de Justicia de la nación adoptaría como parte esencial de estos fallos la doctrina del Control de Convencionalidad desarrollada por la Corte Interamericana de Derechos Humanos.

Así, la figurajurídica delControldeConvencionalidad puede ser empleada por el juez constitucional para resolver una controversia, en donde deberá realizar un análisis y verificación entre las normas y practicas internas que se pretenden aplicar para tutelar un derecho humano o fundamental y su compatibilidad con las disposiciones de la CADH y la jurisprudencia emanada del Tribunal Interamericano relacionada con el bien jurídico que se está tutelando, tomando aun en consideración los casos contenciosos en los cuales Honduras no fue parte de un litigio. Esto significa que el Estado hondureño en el ámbito judicial deberá emplear constantemente el control de convencionalidad tendiente a innovar su jurisprudencia y doctrina legal, para así garantizar de la manera más amplia la dignidad humana.

Como segundo elemento innovador, se contemplaría que la acción de amparo procede no solamente contra actos, hechos o resoluciones de cualquiera de los poderes del Estado, sino, también, contra la actividad de las instituciones sostenidas con fondos públicos y aquellos entes de derecho privado que actúan por delegación de algún órgano del Estado en virtud de concesión, de contrato u otra resolución válida. Esto implicaría conciliar la idea de introducir un nuevo sujeto en la legitimación pasiva y, por extensión, ampliar el contexto de individuos considerados como trasgresores de derechos humanos y fundamentales.
Esta nueva concepción trataría de seguir la línea de pensamiento de la doctrina legal nacida en el seno del Tribunal Constitucional Federal Alemán en emblemático caso Lüth, en donde se reconocería que los derechos fundamentales, por su rango constitucional, generan un efecto irradiador al resto del ordenamiento jurídico de rango secundario, esto crearía la noción legal que estos derechos deben ser respetados de igual forma por los particulares en relación con otros particulares. Por tanto, los individuos en el ejercicio de sus relaciones interindividuales, eventualmente, pueden vulnerar estos preceptos jurídicos, razón por la cual sus actos también deberán ser susceptibles de amparo y objeto de la justicia constitucional. (González, 2012).

Sin embargo, en el caso de Honduras el efecto irradiador de los derechos fundamentales tiene una intención parcial o restringida, toda vez que la normativa considera que la eficacia de estos derechos en las relaciones individuales será de carácter mediato o indirecto, en virtud que se basa en la idea que esta gama de derechos no pueden incidir por sí solos en las relaciones privadas, pues siempre se requerirá la existencia de un acto estatal (otorgamiento de concesión, contrato etc.) que medie entre el derecho y el particular al que se le opone.

Pese a lo anterior, el surgimiento de los Tribunales especializados en la defensa, protección y promoción de los derechos humanos en el ámbito internacional, en especial, los criterios jurisprudenciales desarrollados por la Corte Interamericana de Derechos Humanos desempeñarían un papel fundamental para el desarrollo normativo de la acción de amparo como mecanismo judicial idóneo para proteger la dignidad humana.

\section{PRECISIONES DE LA CORTE IDH RESPECTO A LA PROTECCIÓN JUDICIAL:}

Honduras al ser Estado parte de la Convención Americana sobre Derechos Humanos desde 1977 y tras haber aceptado la cláusula de competencia 
contenciosa de la Corte Interamericana de Derechos Humanos en el año 1981, contrajo consigo dos grandes obligaciones internacionales en relación con los habitantes que se encuentran sometidos a su jurisdicción. La obligación de respeto, la cual implica una noción axiológica jurídica de carácter negativo, se traduce en la abstención de los agentes estatales de coartar arbitrariamente el goce y ejercicio de los derechos humanos y; la obligación de garantía, se refiere a que el Estado en su objetivo de salvaguardar los derechos convencionales deberá adoptar todas aquellas medidas de carácter legislativo, administrativo, judicial o de otra índole que permitan hacer efectiva la plena realización de esta gama de derechos.

En ese sentido, la Corte IDH desde su primera sentencia en el caso Velásquez Rodríguez Vs. Honduras sentaría una base jurisprudencial solida en materia de protección y garantía de los derechos de los ciudadanos, partiendo de la premisa que conforme al preámbulo del Pacto de San José la justicia interamericana será de carácter coadyuvante o complementario de la protección que ofrece el derecho interno del Estado. De tal manera que, en caso de existir vulneraciones a derechos humanos o fundamentales, el Estado al ser el principal garante de los derechos de las personas, le corresponderá, en primera instancia, resolver el asunto a nivel interno, y, en su caso, reparar antes de tener que responder ante las instancias internacionales.

Para acatar el mandato convencional que antecede, las altas partes contratantes deberán brindar el acceso a un recurso judicial ante un juez o tribunal competente, independiente e imparcial que reúna las características procesales conforme a los principios del derecho internacional generalmente reconocidos, dicho de otra manera, aquellos mecanismos legales que una vez analizadas las circunstancias fácticas de cada caso resulten ser adecuados y efectivos para atender con especialidad la lesión del derecho humano o fundamental, esto quiere decir que el acceso a los recursos o acciones judiciales proporcionadas por el Estado deberán estar previamente establecidos en el ordenamiento jurídico y tendrán el cometido de tutelar una situación vulneratoria individualizada, en consecuencia, los efectos jurídicos de estos medios de protección judicial tienen que ofrecer la perspectiva de cesar o reparar el daño al bien jurídico conculcado.

Sobre este particular es importante que la Corte IDH llegaría a la conclusión en sus opiniones consultivas $8 / 87$ y 9/87 que el texto del Art. 25 convencional es una disposición de carácter general que recoge la institución procesal del amparo, entendido como el procedimiento sencillo y breve que tiene por objeto la tutela de todos los derechos reconocidos por las constituciones, leyes de los Estados parte y por la Convención.

Así pues, la Corte IDH en un sentido exegético plasmaría de su jurisprudencia los principios procesales que rigen la acción de amparo, a saber: a) sencillez, b) rapidez y; c) efectividad. Sobre los dos primeros estándares internacionales, el Tribunal Interamericano no ha desarrollado jurisprudencialmente sus concepciones y, en atención a ello, para poder realizar una precisión conceptual y delimitar sualcance normativo, se puede recurrir a emplear una interpretación gramatical conforme al articulo 31 de la convención de Viena sobre el derecho de los tratados. De esta manera, puede decirse que la sencillez consiste en regular el juicio de amparo de forma tal que resulte fácil la realización de su fin convencional, eliminando todos aquellos formalismos presentes en el procedimiento de la garantía constitucional, desde su interposición hasta la resolución, que dificulten la defensa de los derechos humanos.

Sobre esta línea de pensamiento, la Corte IDH llegaría a un razonamiento jurídico que podría asemejarse a la definición del principio de sencillez, en donde señalaría:

El derecho a la tutela efectiva exige a los jueces que dirijan el proceso de modo a evitar que dilaciones y entorpecimientos indebidos, conduzcan a la impunidad, frustrando así la debida 
protección judicial de los derechos humanos, y que los jueces como rectores del proceso tienen el deber de dirigir y encausar el procedimiento judicial con el fin de no sacrificar la justicia y el debido proceso legal en pro del formalismo y la impunidad. (Suarez Peralta Vs. Ecuador, 2013).

Por tanto, el requisito de procedencia de los juicios de amparo deberá mantenerse conforme a los estándares mínimos fijados en la normativa internacional respecto a la intangibilidad del debido proceso, ya que en palabras de la Corte IDH "las formalidades requeridas para que el recurso sea admitido deben ser mínimas y no deben constituir un obstáculo para que el recurso cumpla con su fin de examinar y resolver los agravios sustentados por el recurrente". (Mohamed Vs. Argentina, 2012). De manera que, al existir demasiados requisitos formales que deben cumplir o indicar las partes en su escrito de interposición de la garantía constitucional, en cierta medida se incumplen con los principios de sencillez, tutela judicial efectiva y principio pro-persona.

Por otro lado, la rapidez podrá entenderse como la manifestación contenida en el ordenamiento jurídico que permita ser juzgado con prontitud, impidiendo la prolongación de los plazos y prescindir de trámites procesales superfluos que generen una dilación indebida. Así, el juzgador deberá estar obligado a cumplir con el principio de perentoriedad de los plazos legales o judiciales, ya que la Corte IDH se ha manifestado en el sentido que "la tutela judicial efectiva exige a los jueces que dirijan el proceso en forma que eviten dilaciones y entorpecimientos indebidos que conduzcan a la impunidad, frustrando así la debida protección de los derechos humanos". (Myrna Mack Chang Vs. Guatemala , 2003).

Finalmente, la efectividad es seguramente el criterio más importante y trascendente para el juicio de Amparo. Al igual que los principios de sencillez y rapidez, su incumplimiento afecta a todo el procedimiento, desde su inicio hasta la ejecución de la sentencia. Así pues, este principio se constituye bajo dos tipos de criterios que, a su vez, guardan una intima relación entre sí. Por un lado, existe el elemento de la capacidad del mecanismo legal de consagrar normativamente y en su espíritu jurídico la misión de cesar los daños ocasionados al agraviado y; por otro, la obligatoriedad del cumplimiento de las decisiones y ordenes recaídas en las sentencias de Amparo, en virtud que para garantizar plenamente los derechos humanos y fortalecer el Estado de derecho resulta imperativo que la autoridad de la cual emano en principio la vulneración sea obligada a enmendar su comportamiento, esto a su vez, senvirá como correctivo de las futuras acciones u omisiones que puedan dar lugar a una lesión a la dignidad humana.

Sobre este punto, es importante subrayar lo establecido por la magistratura interamericana en donde se manifiesta que: "La efectividad de las sentencias depende de su ejecución. El Proceso debe tender a la materialización de la protección del derecho reconocido en el pronunciamiento judicial mediante la aplicación idónea de dicho pronunciamiento". (Acevedo Jaramillo Vs. Perú, 2006). En ese orden de ideas, las autoridades que se rehúsen acatar el mandato judicial recaído en las sentencias de Amparo no solamente incurren en su responsabilidad penal por el delito de abuso de autoridad, sino también comprometen la responsabilidad internacional del Estado hondureño por vulneraciones al derecho contenido en el Art. 25 del Pacto de San José.

\section{PROBLEMAS JURÍDICO - NORMATIVOS PRESENTES EN LA LEY SOBRE JUSTICIA CONSTITUCIONAL}

Habiendo expuesto la naturaleza jurídico garantista con que fue concebida la acción de amparo desde sus orígenes y, tras observar que el Estado de Honduras es signatario de instrumentos internacionales de protección de derechos humanos, se puede apreciar que los Juzgadores cuentan con un marco amplio de posibilidades para realizar una impartición de justicia con un enfoque 
de derechos humanos, principalmente cuando se trata de las acciones de Amparo, pues a través de este mecanismo judicial el Estado brinda una reparación al bien jurídico vulnerado producto de las arbitrariedades de las esferas del poder público, empleándolo así como una herramienta fundamental para contrarrestar la brecha existente entre el ideal normativo y la realidad social.

Lo anterior abre la posibilidad de interpretar la aplicación de las leyes en casos concretos de acuerdo con un bloque de constitucionalidad, es decir, la utilización de un acervo de principios jurídicos que, sin aparecer formalmente en el articulado del texto de la Carta Magna, podrán ser utilizados por los jueces como parámetros para verificar la correspondencia entre los actos emitidos por quienes decretan el poder y su concordancia con el espíritu legal de la constitución y tratados internacionales. Es importante resaltar que dentro de estos fundamentos imprescindibles para la justicia con enfoque en derechos humanos es necesario emplear el principio pro homine de protección a los derechos humanos para resolver las controversias que se planteen en torno a cada derecho.

En este orden de ideas, el principio pro homine se erige como una tesis hermenéutica que establece que toda autoridad perteneciente al poder judicial, legislativo o ejecutivo debe aplicar la norma o la interpretación más favorable a la persona o a la comunidad, la cual asegure de la forma más amplia la efectividad de los derechos humanos desde una perspectiva democrática. De esta manera, el Juzgador podrá a través de sus sentencias de Amparo dotar de contenido o ampliar el alcance jurídico de un derecho, estableciendo una serie de estándares y/o conceptualizaciones normativas que constituyan un límite o un mínimo que no puede sobrepasarse, en el sentido que si se retrocede se afecta el contenido esencial de ese derecho. (Meza, 2012)

Por tal motivo, el presente acápite analiza una serie de problemas jurídicos que fueron identificados en la actual Ley sobre Justicia Constitucional que se encuentran en contraposición con las nociones legales expuestas anteriormente y que ha conllevado a un uso limitativo del principio pro homine, lo que produce un debilitamiento en la protección de la dignidad humana.

\section{- La Capacidad de la parte impetrante y efectos jurídicos de la sentencia.}

El Artículo 183 de la Constitución y el Artículo 41 de la Ley sobre Justicia Constitucional consagran la capacidad que tiene toda persona para interponer la garantía constitucional de Amparo. Esta concepción engloba dos aspectos procesales. Por un lado, la legitimación activa para ser parte en el juicio de amparo, condición que tienen todas las personas titulares de un derecho fundamental subjetivo víctimas de un agravio personal y directo, y; por otro lado, se regula la capacidad procesal, lo que en palabras del Jurista Giussepe Chiovenda deberá entenderse como "la facultad para comparecer en juicio, o sea para realizar actos procesales con efectos jurídicos en nombre o en representación de otro" (Chiovenda, 1977).

Conforme a la exegesis que el legislador hondureño ha plasmado en las disposiciones que anteceden, se contempla que la protección constitucional es exclusiva para resolver los daños causados a una persona individualmente determinada, interpretación que ha sido reiterativa en la jurisprudencia de la Sala de lo Constitucional (Considerando Nro. 4 Expte. AA387-2018); por consiguiente, la eventual sentencia que deniegue u otorgue el amparo, producirá efectos legales únicamente entre las partes intervinientes, es decir, a favor de aquellas personas que figuran en el escrito de formalización de la acción y que comparecen en su condición de agraviado, por tanto, se excluyen pretensiones de carácter colectivo o difuso, pues no se ha reconocido ni conceptualizado el carácter expansivo de la acción con la cual se pueda brindar una cobertura a un número mayor de titulares, aun cuando estos no figuren en el escrito de interposición. 
No obstante, la evolución del derecho constitucional moderno ha permitido ofrecer una senda particular a protecciones especiales, como los derechos del consumidor, la defensa del medio ambiente, la prevención del daño arquitectónico y; el resguardo del patrimonio artístico y cultural. Este medio de protección se concretiza a través de una acción de amparo por derechos colectivos o difusos, cuyo objetivo y espíritu legal se centra en la tutela de los intereses colectivos, y no, sobre la noción subjetiva del individuo. (Gozaíni, 2011).

Sobre este particular es importante resaltar que han existido dos casos emblemáticos en los cuales los recurrentes han pretendido generar un efecto difuso o colectivo de la sentencia recaída en el juicio de amparo. El primer caso corresponde al denominado "hoy no circula" contentiva en el Decreto Ejecutivo PCM - 008 - 2008, mediante el cual el titular del Poder Ejecutivo pretendía impulsar una política de ahorro de combustible limitando el derecho a la libertad de circulación. El Segundo se refiere a la sentencia AA-197-2017, la cual se refiere al aumento de los cobros por servicios que brinda el Hospital Escuela Universitario (H.E.U).

En ambos casos, la sentencia fue resuelta a favor de los recurrentes por lesionar derechos fundamentales; sin embargo, la Sala de lo Constitucional en la parte dispositiva de dichos fallos estableció únicamente que dichos actos de autoridad no obligaban a los peticionarios que figuraban en el escrito o demanda de Amparo. Por tanto, el Tribunal supremo de Justicia no se ha pronunciado sobre los efectos erga omnes del Amparo y, ha establecido únicamente que los facultados para interponer acciones con pretensiones colectivas o difusas por la vía de este mecanismo de garantía constitucional son el Ministerio Público y el Comisionado Nacional de los Derechos Humanos (Considerando 05 AA387-2018), pues estos órganos por su rango constitucional no dirigen o vinculan su acción constitucional con una controversia intersubjetiva concreta, sino que, al contrario, por su objeto y fin actúa a favor de los intereses de la sociedad (ver RI-2895-2003).
Estas consideraciones de la sala ciertamente generan una problemática y limitación a la dignidad humana, pues se estaría interpretando la normativa en el sentido que el individuo no puede desenvolverse como un ser social, el cual proyecte sus intereses subjetivos a una dimensión en donde la vulneración afecta también a estratos colectivos. De esta manera, los criterios de la sala entrarían en una contraposición ontológica, pues cada ciudadano tiene el deber de respetar y hacer cumplir la constitución; deber, que implica conforme al espíritu del efecto irradiador de las normas de derechos fundamentales, respetar y proteger la dignidad humana a través de los medios legales, comportamientos éticos y/o morales posibles.

\section{- Falta de delimitación del criterio subsidiario de la acción de amparo.}

Uno de los requisitos formales para que se declare la admisibilidad de esta garantía constitucional consiste en que el impetrante deberá indicar los recursos legales de los cuales se ha valido para obtener la subsanación del hecho, acto, resolución, orden o mandato contra el cual se reclama, esto en los términos del artículo 49 numeral 3 de la Ley sobre Justicia Constitucional.

Lo anterior obedece a la necesidad de establecer un filtro en el cual la interposición de la acción constitucional de amparo se vea atemperada, esto con el objetivo de evitar un número excesivo de recursos sobre asuntos de escasa importancia. Por tanto, el principio de subsidiariedad implica que, previo a su interposición, se tuvieron que haber presentado todos aquellos recursos que tutelan indirectamente los derechos fundamentales, tales como la reposición, apelación y, en algunos casos a criterio de la Sala de lo Constitucional (AL-11922014), el recurso extraordinario de casación. En consecuencia, se puede apreciar que la Sala ha establecido este tipo de filtros con la finalidad de impedir un funcionamiento irregular del recurso ya que aplican el criterio que la jurisdicción constitucional será la última instancia en la protección de los derechos garantizados. 
En ese orden de ideas, la no interposición de los recursos que anteceden dentro de los términos legales conllevará a que el acto vulneratorio sea considerado como consentido por el agraviado, lo cual constituye una causa justa de declaratoria de inadmisibilidad in limine litis de la acción constitucional en los términos del artículo 46 numeral 3 de la Ley sobre Justicia Constitucional.

El hecho de contemplar esta disposición y que continúe siendo interpretada en ese sentido implica un problema en la desnaturalización conceptual de la condición del agraviado, en virtud que el espíritu de este precepto asume en su contenido una afirmación en la cual la persona directamente afectada es la que ejecuta actos de procuración en la justicia ordinaria o, dicho de otra manera, se asume que el agraviado es quien ejerce a título personal su capacidad procesal.

Si bien es cierto, nuestro derecho adjetivo consagra que, para incoar un proceso ante los tribunales ordinarios, indistintamente de la materia que se trate, debe existir un consentimiento de la parte interesada o peticionaria en otorgar un poder de representación procesal al profesional del derecho, quien estará a cargo únicamente de la defensa técnica. Esto no significa, per se, una condición ilimitada en el cual los actos o hechos realizados por el profesional del derecho manifiesten la voluntad pura del titular del derecho fundamental.

En vía de ejemplo podemos ilustrar un caso hipotético en el cual existe una sentencia de autoridad competente en donde se configura una vulneración a un derecho fundamental como el debido proceso por no haber motivado la sentencia $\mathrm{y}$, ante esta situación el profesional del derecho se encuentra obligado hacer uso de los recursos legales como la apelación para enmendar o revertir el acto vulneratorio. No obstante, si estamos frente a la presencia de una inobservancia del abogado, ya sea por negligencia o impericia imputables a sí mismo, se estaría ante un supuesto en donde no se presentarían acciones legales para impugnar esa decisión.
Por tanto, en cuanto a este elemento su incompatibilidad radica en que resulta fuera de las nociones lógicas y legales a la luz del principio hermenéutico pro homine que la persona afectada este de acuerdo con que se le vulnere un derecho fundamental, lo cual implica desconocer la importancia de la acción de amparo como mecanismo protector directo, adecuado y efectivo de la dignidad humana. Sobre esta línea de pensamiento, el Estado se despojaría de su rol de garante de los derechos de los ciudadanos, pues no analizaría la concurrencia de posibles vulneraciones a esta gama de derechos y permitiría que eventuales actos vulneratorios queden en ausencia total de tutela, agravando la situación jurídica de la persona interesada.

En consecuencia, el uso constante de esta doctrina legal que se remonta a la jurisprudencia reiterativa emitida por la Sala de lo Constitucional en aplicación de la antigua Ley de Amparo de 1936, resulta limitativa para la dignidad humana, pues con dicha disposición se continua otorgando preeminencia al análisis y cumplimiento de los requisitos formales (AL-835-2015; AA-6582016; AC-156-2014) y se sitúa en un segundo plano el aspecto más importante de la protección constitucional, el cual se relaciona con los hechos de fondo constitutivos de violaciones a los derechos del individuo.

\section{- Margen de discrecionalidad entre la Justicia Constitucional y Administrativa}

El ordenamiento jurídico hondureño a través del corpus iuris que regula el derecho administrativo guarda una íntima relación con un determinado aspecto de la garantía constitucional de amparo, esto se refiere a uno de los motivos de invalidez de los actos de la administración pública contemplado en el literal "F" del artículo 34 de la Ley de Procedimiento Administrativo, el cual reza: "Serán nulos los actos administrativos que contraríen lo dispuesto en el artículo 8 de la Ley General de la Administración Pública", es decir, que carecen de 
validez aquellos Decretos, Acuerdos o Resoluciones que disminuyan, restrinjan 0 tergiversen los derechos y garantías reconocidas por la Constitución de la República. Por esta razón, se establece la Jurisdicción Contencioso - Administrativa a fin de que la parte interesada pueda acudir ante esta vía judicial para solicitar la nulidad del acto de carácter general o particular emitido por la administración que reúna tal presupuesto, esto con la finalidad de salvaguardar un derecho subjetivo o el respeto al imperio de la ley.

Sin embargo, el legislador hondureño al momento de aprobar la Ley sobre Justicia Constitucional, en lugar de obtener una armonización del ordenamiento jurídico hondureño en relación con la acción de amparo, paso por alto las disposiciones citadas ut supra y produjo una dualidad normativa, en virtud que atribuyó competencia directa a la Corte Suprema de Justicia a través de su Sala Constitucional para conocer por medio de la acción de amparo sobre aquellos actos, hechos o resoluciones del Presidente de la República o Secretarios de Estado que coartaran indebidamente un derecho humano o fundamental y; por otro lado, mantuvo vigente la disposición en donde permite solicitar la nulidad de un acto administrativo del poder ejecutivo ante la jurisdicción contencioso - administrativa por restringir, disminuir o tergiversar derechos constitucionalmente protegidos.

En ese orden de ideas, ambas figuras jurídicas tienen como característica esencial la impugnación y corrección de una conducta de la autoridad para tutelar los derechos humanos o fundamentales, pero se diferencian por la forma de protección, ya que a través del amparo se ejerce una tutela directa del derecho fundamental $y$, por otro lado, mediante la demanda en la jurisdicción contencioso - administrativa se despliega una protección indirecta a ese derecho, el cual, prima facie, brinda la perspectiva de poder ser abordado por una u otra jurisdicción.

Al respecto, es importante resaltar que el artículo
46 numeral 8 de la Ley sobre Justicia Constitucional establece como causa justa para declarar in limine litis la inadmisibilidad de la acción de amparo "cuando se tuvieren expeditos recursos o acciones legales en la vía contencioso - administrativa". El principal inconveniente que surge al establecer este motivo como criterio de improcedencia radica en el otorgamiento de un margen de discrecionalidad al juzgador que está conociendo sobre la causa de amparo, el cual por la situación planteada y el tipo de acto sobre el cual se reclama puede decidir con flexibilidad sobre el otorgamiento o no del amparo.

Ciertamente este discernimiento puede producir la comisión de actos arbitrarios de la autoridad judicial, en virtud que si se reclama mediante un amparo que un Decreto, Acuerdo o Resolución de los órganos de la administración pública vulneran un derecho fundamental, el juzgador puede deponer el conocimiento de esta acción por el simple hecho de que el agraviado no ha ejercitado la acción judicial de interponer una demanda ante la jurisdicción contencioso - administrativa, en donde se solicite la nulidad del acto por disminuir, restringir o tergiversar ese derecho. Por tanto, esta disposición somete, en algunos casos, la protección de los derechos humanos o fundamentales a un mero formalismo, ya que se despoja de la naturaleza prioritaria de protección y da lugar a que las controversias provenientes del Presidente de la República o sus Secretarios de Estado sean dirimidos en la justicia ordinaria, lo que produciría que el estatus de protección de los derechos humanos o fundamentales adquiera una connotación de segundo plano y; las implicaciones jurídicas de someter un caso ante la jurisdicción contencioso - administrativa para tutelar derechos humanos o fundamentales provocarían que el prolongamiento del proceso cause un impacto mayor a la situación jurídica de la persona interesada.

\section{CONCLUSIONES:}

- Para finalizar el presente artículo científico se destacan los siguientes aspectos. La garantía constitucional de Amparo tendría en 
sus inicios una historia marcada por muchos desaciertos normativos, los cuales pueden clasificarse en dos categorías atendiendo al momento histórico en que regularon la justicia constitucional hondureña. Así, la primera categoría hace alusión a las leyes de Amparo comprendidas entre los años 1893 a 1936 , dentro de las cuales se identificaron obstáculos jurídicos tales como la ausencia del principio de prelación del amparo, la falta de celeridad y economía procesal, aunado a la flexibilidad de extensión de plazos y mandatos judiciales por distancia territorial, estos impedimentos de carácter eminentemente procesal serian recurrentes entre la transición de una ley y otra, pues cada una de estas leyes de caracterizaría por ser una copia reiterada de las disposiciones de su predecesora, esto fue debido a la caótica historia constitucional hondureña producto de los golpes de Estado, derogación y emisión de nuevas Constituciones, ello obliteraría la protección de los derechos fundamentales, pues el juicio de amparo se convertiría en una vía judicial extremamente engorrosa.

- La segunda categoría comprende la promulgación de la Ley sobre Justicia Constitucional, en esta etapa ciertamente se enmendarían los inconvenientes procesales identificados en las leyes anteriores, mediante el reconocimiento de principios que permitieron efectivizar la tramitación del juicio de garantías; no obstante, los obstáculos jurídicos que se presentan en esta ley se enmarcan en elementos que se relacionan con el fondo o finalidad de la acción, pues destacan aspectos como el desconocimiento de pretensiones colectivas o difusas, la existencia de causas de inadmisibilidad de la acción por no agotar otros recursos judiciales que no guardan relación con una protección directa de los derechos fundamentales $\mathrm{y}$; finalmente, la discrecionalidad normativa en vías jurisdiccionales.
- En ese orden de ideas, estos problemas jurídicos tienen una naturaleza bipartita. Por un lado, se destaca el aspecto normativo, en virtud que se consagran disposiciones cuyo contenido legal establecen pautas rígidas y en extremo formales que limitan la actividad del juzgador para efectuar interpretaciones flexibles y extensivas en su actividad judicial, ya que preceptos de la Ley sobre Justicia constitucional tales como los denominados "actos consentidos por el agraviado", "procedencia de la acción”, "agotamiento de recursos previos" o "sujetos de la acción de amparo”, entre otros, el Legislador optó por indicar la terminología en la cual deben ser interpretadas dichas disposiciones, limitando la participación de la discrecionalidad del juzgador para tomar en cuenta otras variables que influyen en un caso de acuerdo a las particularidades que presente cada denuncia de vulneración a los derechos humanos o fundamentales.

- Como segunda acotación resalta el aspecto jurisprudencial, el cual, dicho sea de paso, es una consecución del elemento normativo, pues los jueces si bien actúan dentro del principio de legalidad, han limitado su actividad hermenéutica, pues la jurisprudencia reiterativa aplicada actualmente por la Sala de lo Constitucional deriva de la doctrina legal que dejó la antigua Ley de Amparo de 1936. A pesar de que la Ley sobre Justicia Constitucional le atribuye potestad a la Sala constitucional de cambiar su doctrina legal, ésta ha permanecido pasiva respecto a la ampliación de novedosas conceptualizaciones garantistas, manteniéndose dentro de un margen conservador.

- Todo lo anterior se encuentra en contraposición con postulados garantistas tales como el principio pro homine, y que, a su vez, limitan la dignidad humana del individuo, en virtud que no se han desarrollado efectivamente 
conceptualizaciones, estándares y/o principios que amplíen el marco de protección de un derecho, lo que se traduce en la ausencia de nuevos significados normativos para los derechos humanos o fundamentales.

- Por todo lo expuesto surge la necesidad de emprender reformas a la Ley sobre Justicia Constitucional, tendiente a flexibilizar la norma actual, estableciendo un mínimo normativo que le permita más tarde al Juzgador dotar y ampliar su contenido a través de su jurisprudencia, ello con una visión de garantizar una justicia con enfoque en derechos humanos.

\section{BIBLIOGRAFÍA:}

- Acevedo Jaramillo Vs. Perú, 157 (Corte Interamericana de Derechos Humanos 7 de febrero de 2006).

- Chiovenda, G. (1977). Principios de Derecho Procesal Civil. Reus (S.A.).

- Fernández, F. S. (1995). La dignidad de la persona en el ordenamiento constitucional español. Revista Vasca de Administración Pública, 49.

- González, B. B. (2012). Antecentes de la eficacia de los derechos fundamentales entre particulares, y la dogmática constitucional. En El Amparo contra actos de particulares (págs. 7 y 8; 12 - 15). Ciudad de Panamá: Universal Books.

- Gozaíni, O. A. (2011). El Amparo y la Defensa de los Derechos Colectivos. En E. F. Gregor, \& E. D. Rojas, La Protección Órganica de la Constitución (pág. 88 y 94). México: Instituto de Investigaciones Jurídicas de la U.N.A.M.

- Meza, J. N. (2012). El impacto de la reforma constitucional en materia de derechos humanos en la labor jurisdiccional en México. En R. S. Ricci, Derecho Constitucional de los Derechos Humanos (pág. 85). Distrito Federal, México: Porrúa-Escuela Libre de Derecho.

- Mohamed Vs. Argentina, 255 (Corte Interamericana de Derechos Humanos 23 de noviembre de 2012).

- Myrna Mack Chang Vs. Guatemala , 101 (Corte Interamericana de Derechos Humanos 25 de noviembre de 2003).

- Poisot, E. F.-G. (2010). El Amparo Iberoamericano . En E. F.-G. Poisot, Juicio de Amparo y Derecho Procesal Constitucional (pág. 233). Santo Domingo.

- Suarez Peralta Vs. Ecuador, 261 (Corte Interamericana de Derechos Humanos 21 de mayo de 2013).

- Yupanqui, S. A. (2004). El Proceso Constitucional de Amparo. En Derecho Procesal Constitucional (pág. 677). Lima. 